\title{
Use of the shifting method results for PID controllers parameters estimation
}

\author{
Alžběta Hornychová ${ }^{1, *}$ and Milan Hofreiter ${ }^{1, * *}$ \\ ${ }^{1}$ CTU in Prague, Faculty of Mechanical Engineering, 16607 Prague 6, Czech Republic
}

\begin{abstract}
This paper presents the use of the results of the shifting method of relay feedback identification for tuning the Proportional-Integral-Derivative controllers. Parameters of the second order plus time delay models estimated by the shifting method of relay feedback identification were used to compute controller parameters. Behaviour of closed loop systems with tuned controllers was tested and compared for three simulated systems and one real laboratory system. All tests were performed on the programmable logic controller Tecomat Foxtrot. In all the studied cases the use of the tuned controllers resulted in correct control of the system.
\end{abstract}

\section{Introduction}

Identification is an important part of control engineering, because correct identification is the first step in controllers tuning. With relay feedback identification, the controlled plant is under control at all times. Therefore, new methods of relay identification keep to be proposed. The recently published shifting method [1] finds two points of a Nyquist frequency characteristics from a single relay feedback test. It allows for estimating all parameters of second order plus time delay model (SOTD) [2], [3], [4].

\subsection{PID parameters estimation}

There are many methods of PID parameters estimation. Some are based on the SOTD model

$$
M(s)=\frac{K \cdot e^{-s \cdot \tau_{u}}}{a_{2} s^{2}+a_{1} s+1},
$$

where $K$ is a static gain, $\tau_{u}$ is a transport delay and $a_{2}$, $a_{1}$ are parameters of a characteristic polynomial. For nonoscillatory systems, a derived model

$$
M(s)=\frac{K \cdot e^{-s \cdot \tau_{u}}}{\left(T_{1} s+1\right)\left(T_{2} s+1\right)},
$$

is most often used, where $T_{1}$ and $T_{2}$ are a time constants, while for oscillatory systems

$$
M(s)=\frac{K \cdot e^{-s \cdot \tau_{u}}}{T_{0}^{2} s^{2}+2 \xi_{0} T_{0} s+1},
$$

may be applied, where $\xi_{0}$ is damping and

$$
T_{0}=\frac{1}{\omega_{0}},
$$

where $\omega_{0}$ is the natural frequency.

\footnotetext{
*e-mail: Alzbeta.Korabkova@fs.cvut.cz

**e-mail: Milan.Hofreiter@fs.cvut.cz
}

In this contribution, we used the outcomes of the shifting method of relay feedback identification of three simulated systems from [4] and one real laboratory controlled plant from [5] to compute the parameters of PID controller using up to four methods of PID parameter estimation. We demonstrate that the results of the shifting method can be used in control of the systems in question.

\section{Methods}

In this paper we used four PID controller tuning methods. All of them compute PID parameters from SOTD model. The AMIGO method [6] was developed for tuning of controller for non-oscillatory systems control. Second method is based on phase margin criterion [7]. This method can be used for non-oscillatory systems. Dynamic inversion method [8] allows for estimating PID parameters for nonoscillatory and oscillatory systems with damping $\xi_{0}>0.5$. The parameters are calculated according to requirement set on the value of controlled variable overshoot. The simple control method [9] tunes PID parameters for nonoscillatory systems control only.

For all methods we used the PID controller with the following transfer function:

$$
R(s)=r_{0}\left(1+\frac{1}{s T_{i}}+s T_{d}\right)
$$

We calculated the PID parameters with programmable logic controller (PLC) Tecomat Foxtrot (TECO, Kolín, Czech Republic). Program for PLC was written in programming language Structured text according to IEC 61131-3 in programming environment MOSAIC [10].

\subsection{The AMIGO tuning rules for PID controllers}

The AMIGO PID controllers tuning rules are based on the model (2) [6]. The controller parameters could be calcu- 
late from equations

$$
\begin{gathered}
r_{0}=\frac{0.19}{K}+\frac{0.37 T_{1}+0.18 T_{2}}{K \cdot \tau_{u}}+\frac{0.02 T_{1} T_{2}}{K \cdot \tau_{u}^{2}}, \\
r_{i}=\frac{0.48}{K \cdot \tau_{u}}+\frac{0.03 T_{1}-0.0007 T_{2}}{K \cdot \tau_{u}^{2}}+\frac{0.0012 T_{1} T_{2}}{K \cdot \tau_{u}^{3}}, \\
T_{i}=\frac{r_{0}}{r_{i}},
\end{gathered}
$$$$
r_{d}=\frac{T_{1}+T_{2}}{K\left(T_{1}+T_{2}+\tau_{u}\right)}\left(0.29 \tau_{u}+0.16 T_{1}+0.2 T_{2}+\frac{0.28 T_{1} T_{2}}{\tau_{u}}\right)
$$$$
T_{d}=\frac{r_{d}}{r_{0}}
$$

for $T_{1}>T_{2}[6]$.

\subsection{Phase margin criterion (PMC) based PID controllers tuning}

This method sets PID parameters by requiring that controlled closed loop phase margin value is $\pi / 4$ [7]. Parameters calculation is based on the models (1) and (2). The PID control parameters are estimated with equations [7]:

$$
\begin{gathered}
r_{i}=\frac{\pi}{4|K| \tau_{u}}, \\
T_{i}=\frac{r_{0}}{r_{i}}, \\
r_{0}=\left(T_{1}+T_{2}\right) r_{i}=a_{1} \cdot r_{i}, \\
r_{d}=T_{1} T_{2} r_{i}=a_{2} \cdot r_{i}, \\
T_{d}=\frac{r_{d}}{r_{0}} .
\end{gathered}
$$

\subsection{The dynamics inversion method (DIM) of tuning PID controllers}

The method is based on the model (3) for oscillatory systems [8] with

$$
0.5<\xi_{0}<1 \text {. }
$$

The controller parameters can be calculated also from the model (1) using equations

$$
\begin{gathered}
T_{i}=2 \xi_{0} T_{0}+T=a_{1}+T, \\
r_{0}=\frac{a T_{i}}{K}, \\
a=\frac{1}{\alpha T+\beta \tau_{u}}, \\
T_{d}=\frac{T_{0}}{2 \xi_{0}}+\frac{T}{4}=\frac{a_{2}}{a_{1}}+\frac{T}{4},
\end{gathered}
$$

where $T$ is the sampling period of a discrete PID controller [8].
Table 1. Values of $\alpha$ and $\beta$ according to the value of controlled variable overshoot $\kappa[8]$

\begin{tabular}{l|llllll}
\hline$\kappa$ & 0 & 0.05 & 0.1 & 0.15 & 0.2 & 0.25 \\
\hline$\alpha$ & 1.282 & 0.984 & 0.884 & 0.832 & 0.763 & 0.697 \\
$\beta$ & 2.718 & 1.944 & 1.720 & 1.561 & 1.437 & 1.337 \\
\hline
\end{tabular}

\subsection{The simple control (SIMC) tuning rules for ideal PID controllers}

The SIMC PID rules for PID controller (5) are based on ' the non-oscillatory model (2) [9].

If $T_{1}<=8 \tau_{u}$ and $T_{1}>T_{2}$, then

$$
\begin{gathered}
r_{0}=\frac{0.5}{K} \frac{T_{1}+T_{2}}{\tau_{u}}, \\
T_{i}=T_{1}+T_{2}=a_{1}, \\
T_{d}=\frac{T_{2}}{1+\frac{T_{2}}{T_{1}}}[9] .
\end{gathered}
$$

If $T_{1} .=8 \tau_{u}$ and $T_{1}>T_{2}$, then

$$
\begin{gathered}
r_{0}=\frac{0.5}{K} \frac{T_{1}}{\tau_{u}}\left(1+\frac{T_{2}}{8 \tau_{u}}\right), \\
T_{i}=8 \tau_{u}+T_{2}, \\
T_{d}=\frac{T_{2}}{1+\frac{T_{2}}{8 \tau_{u}}}[9] .
\end{gathered}
$$

\section{Control of systems with tuned PID controllers}

System control started at null conditions. The command variable was set at 5. Quality of the control was compared between the PID controller tuning methods based on the time of control $T_{c}$, the value of overshoot $O S_{c}$ and the integral of time multiplied by squared error $E r_{c}$.

\subsection{Example 1: simulated lag dominated process}

Identification of the system

$$
P_{1}(s)=\frac{1}{(s+1)(0.1 s+1)(0.01 s+1)(0.001 s+1)}
$$

has been performed by Hofreiter \& Hornychová [4], resulting in model

$$
M_{1}(s)=\frac{1 \cdot e^{-0.011 s}}{0.1 s^{2}+1.1 s+1} .
$$

PID parameters calculated based on the identified model (28) and parameters of control process are presented in tab. 2. The control processes are compared in fig. 1 for all the four tuning methods. 
Table 2. Example 1 - parameters of PID controllers and control processes

\begin{tabular}{l|llll}
\hline & AMIGO & PMC & DIM & SIMC \\
\hline$r_{0}$ & 51.99 & 78.54 & 36.79 & 97.11 \\
$T_{I}[s]$ & 0.1364 & 1.1 & 1.1 & 0.188 \\
$T_{D}[s]$ & 0.05196 & 0.09091 & 0.09091 & 0.04681 \\
\hline$T_{c}[s]$ & 1.38 & 7.38 & 7.42 & 1.48 \\
$\operatorname{Er}_{c}[s]$ & 445.5 & 2414 & 2490 & 447.4 \\
$O S_{c}[\%]$ & 0.98 & 0 & 0 & 0 \\
\hline
\end{tabular}

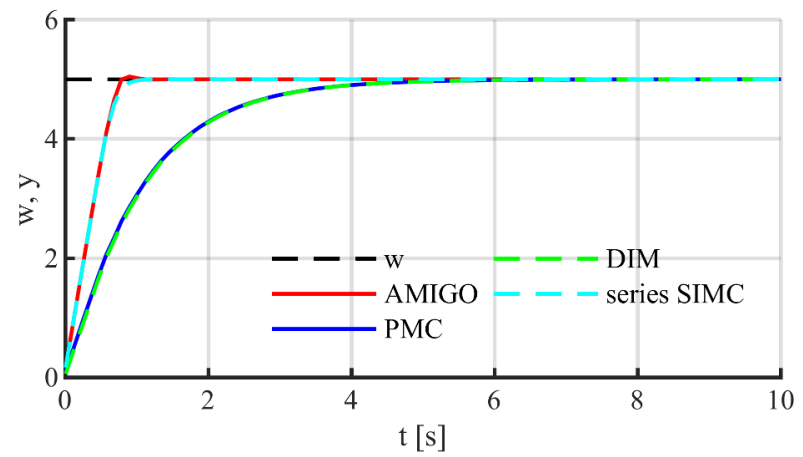

Figure 1. Example 1 - results of system control with tuned PID controllers.

\subsection{Example 2: simulated balanced process}

Simulated balanced controlled plant with transfer function

$$
P_{2}(s)=\frac{1}{(s+1)^{4}}
$$

was identified [4] as a system with oscillatory model

$$
M_{2}(s)=\frac{0.9535 \cdot e^{-0.956 s}}{3.084 s^{2}+2.942 s+1} .
$$

PID parameters calculated based on the identified model and parameters of control process are presented in tab. 3 . Because the model was identified as oscillatory, only PMC and DIM method were used. The control processes are compared in fig. 2 for both tuning methods.

Table 3. Example 2 - parameters of PID controllers and control processes

\begin{tabular}{l|ll}
\hline & PMC & DIM \\
\hline$r_{0}$ & 2.535 & 1.187 \\
$T_{I}[s]$ & 2.942 & 2.942 \\
$T_{D}[s]$ & 1.048 & 1.048 \\
\hline$T_{c}[s]$ & 15.17 & 19.00 \\
$\operatorname{Er}_{c}[s]$ & 46453 & 78854 \\
$O S_{c}[\%]$ & 1.8 & 1.2 \\
\hline
\end{tabular}

\subsection{Example 3: simulated delay dominated process}

Simulated delay dominated controlled plant with transfer function

$$
P_{3}(s)=\frac{1 \cdot e^{-s}}{(0.05 s+1)^{2}}
$$

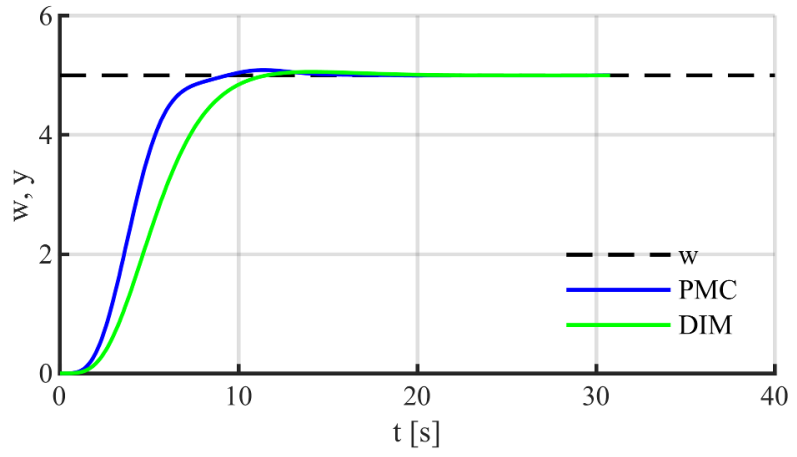

Figure 2. Example 2 - results of system control with tuned PID controllers.

was identified [4] as a system with oscillatory model

$$
M_{3}(s)=\frac{1 \cdot e^{-0.955 s}}{0.00856 s^{2}+0.1486 s+1} .
$$

PID parameters calculated according to identified model (32) and parameters of control process are in tab. 4. Because of identified oscillatory model only PMC and DIM method were used. Control processes are compared in fig. 3 for both tuning methods.

Table 4. Example 3 - parameters of PID controllers and control processes

\begin{tabular}{l|ll}
\hline & PMC & DIM \\
\hline$r_{0}$ & 0.1222 & 0.05725 \\
$T_{I}[s]$ & 0.1486 & 0.1486 \\
$T_{D}[s]$ & 0.05760 & 0.05760 \\
\hline$T_{c}[s]$ & 9.34 & 21.31 \\
$\operatorname{Er}_{c}[s]$ & 3522 & 14035 \\
$O S_{c}[\%]$ & 0 & 0 \\
\hline
\end{tabular}

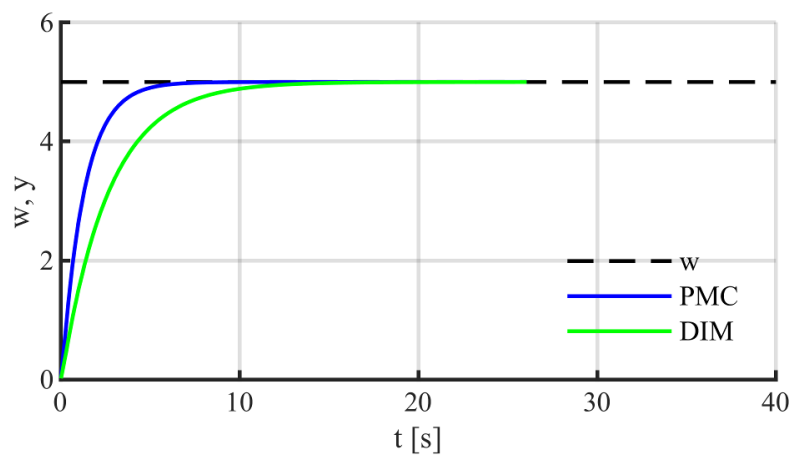

Figure 3. Example 3 - results of system control with tuned PID controllers.

\subsection{Example 4: real laboratory controlled plant}

Real laboratory controlled plant called "Air Aggregate" consists of a fan and a flow rate meter. Action variable is voltage on the fan (which regulates its power output) and controlled variable is voltage on the flow rate meter 
(which depends on the air flow rate created by the fan). The plant was identified [5] with model

$$
M_{5}(s)=\frac{1.969 \cdot e^{-3.89 s}}{0.0044 s^{2}+8.315 s+1} .
$$

The resulting PID parameters and parameters of control process are presented in tab. 5, the control processes are compared in fig. 4.

Table 5. Example 4 - parameters of PID controllers and control processes

\begin{tabular}{l|llll}
\hline & AMIGO & PMC & DIM & SIMC \\
\hline$r_{0}$ & 0.4982 & 0.8526 & 0.3994 & 0.5428 \\
$T_{I}[s]$ & 7.012 & 8.315 & 8.315 & 8.315 \\
$T_{D}[s]$ & 1.708 & 0.00053 & 0.00053 & 0.00053 \\
\hline$T_{c}[s]$ & 50 & 50 & 67 & 48 \\
$E r_{c}\left[V^{2} s\right]$ & $8.1 \mathrm{e}+03$ & $1.0 \mathrm{e}+04$ & $2.2 \mathrm{e}+04$ & $1.6 \mathrm{e}+04$ \\
$O S_{c}[\%]$ & 38.7 & 2.2 & 0.6 & 1.5 \\
\hline
\end{tabular}

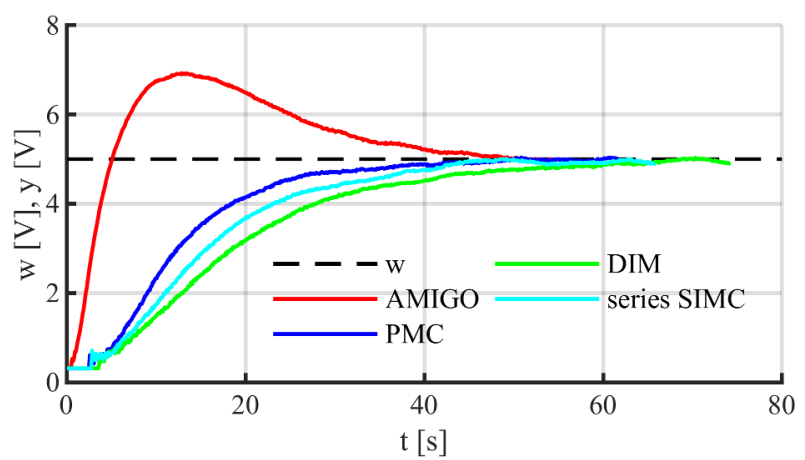

Figure 4. Example 4 - results of system control with tuned PID controllers.

\section{Concluding remarks}

The models identified by the shifting method were successfully used to set PID controllers following four dif- ferent methods so that the controlled systems reached the command variable value that we set. All methods worked well with minimal values of overshoot on all the identified systems, except for the AMIGO method, which exhibited considerable overshoot in the real laboratory system. Successful use of the PLC for control of the identified systems indicates the possible future use of the shifting method in practice.

This work was supported by the Grant Agency of the Czech Technical University in Prague, grant Mo. SGS19/158/OHK2/3T/12.

\section{References}

[1] M. Hofreiter, IFAC-PapersOnLine 49, 1933-1938 (2016)

[2] M. Hofreiter, IFAC-PapersOnLine 50, 1462-1465 (2017)

[3] M. Hofreiter, IFAC-PapersOnLine 51, 891-896 (2018)

[4] M. Hofreiter, Process Identification Using Relay Shifting Method for Auto Tuning of PID Controller (to be published)

[5] M. Hofreiter, Improved relay feedback identification using shifting method (to be published)

[6] J. Berner, T. Hägglund, and K. J. Åström, American Control Conference (ACC), IEEE, 1869-1875 (2016)

[7] M. Hofreiter, Základy automatického ř́zení, (Nakladatelství ČVUT, Praha, 2016)

[8] B. Šulc and M. Vítečková, Teorie a praxe návrhu regulačních obvodi̊, (Vydavatelství ČVUT, Praha, 2004)

[9] S. Skogestad, Modeling, identification and control 25, 85-120 (2004)

[10] PLC programming according to the IEC 61 131-3 standard in the Mosaic environment, online: https://www.tecomat.com/download/get/txv00321_02_ mosaic_progiec_en/163/ 